\title{
MÉTODOS DE SELEÇÃO DE SECADORES
}

\author{
Luís Felipe Toro ALONSO , Kil Jin PARK
}

\section{RESUMO}

Quando uma etapa de secagem faz-se necessária, o engenheiro deve escolher um secador adequado que se integre no processo como um todo. E ele deverá comparar as vantagens e desvantagens dentre as várias alternativas disponiveis tomando em conta tanto o ponto de vista técnico como o econômico. Alguns autores escrevem sobre a seleção de secadores. Embora cada autor desenvolva seleção dos secadores de um modo próprio, identifica-se uma linha geral no procedimento de escolha do equipamento. Todos os autores estabelecem um roteiro ou um fluxograma com questionamentos segundo os quais somos dirigidos ao equipamento mais apropriado. De uma breve revisão sobre o tema, podemos notar dois mecanismos básicos para o desenvolvimento da seleção de secadores: analítico - em que uma seqüência de processos decisórios elimina os equipamentos inadequados à solução, conduzindo à determinação da melhor solução; numérico - em que cada equipamento recebe uma pontuação de acordo com a sua adequação à solução do problema, na totalização, a melhor solução é a que obtém a maior pontuação. Neste artigo são apresentados os resultados da seleção de secadores obtidos em um novo modelo de seleção proposto por ALONSO [2].

Palavras-chave: seleção; secador; método.

\section{SUMMARY}

DRYER SELECTION METHODS. When a drying step is needed, the engineer must choose the most adequate equipment, which must fit into the whole process. He must compare the advantages and disadvantages among the many available choices considering both technical and economic aspects. Some authors describe the dryer selection. Even though each author develops his or her own dryer selection, a general guideline in their dryer selection models may be identified. Every author establishes a query or a flowchart by which through its inquiry we are guided to the most appropriate equipment. From a brief review, one may notice two basic procedures for dryer selection: analytical by which a series of process decision eliminates the inappropriate equipment to the problem solution, leading to the best solution; numeric - by which each equipment is awarded a sum of points according to its adequacy to the problem solution, the solution showing the highest sum is assumed the best solution. In this paper the results achieved in a new dryer selection was conceived by ALONSO [2].

Keywords: selection; dryers; methods.

\section{1 - INTRODUÇÃO}

Uma vez que é necessário o uso da secagem em alguma etapa de processamento, o trabalho do engenheiro se desdobra. Ele deverá escolher um secador adequado que se integre no processo como um todo. E ele deverá comparar as vantagens e desvantagens dentre as várias alternativas disponíveis tomando em conta tanto o ponto de vista técnico como o econômico.

Antes que uma opção final seja feita, quase sempre será necessária uma simulação do comportamento do secador nas condições específicas de processamento.

KEMP \& BAHU [4], bem como LAPPLE, CLARK e DYBDAL [6], indicam que a amplitude de aplicação de alguns secadores é grande e, portanto, a escolha do modelo mais adequado pode ser subjetiva, baseada no bom senso e experiência do engenheiro. VAN'T LAND [11] inicia a seleção dos secadores com base nas informações sobre o produto a ser processado e volume de processamento.

Recebido para publicação em 05/03/2002. Aceito para publicação em 06/05/2005(000810).

Faculdade de Engenharia Agrícola, Universidade Estadual de Campinas (UNICAMP). E-mail: lfta@estadao.com.br, lfta@ig.com.bre kil@agr.unicamp.br

A quem a correspondência deve ser enviada.
KEMP \& BAHU [4] desenvolvem a seleção dos secadores atribuindo pontuações a diferentes características dos equipamentos e encerra selecionando os mais aptos à tarefa. BAKER \& LABADIBI [3] aplicam os princípios de lógica difusa no desenvolvimento da seleção. MATASOV, MENSHUTINA \& KUDRA [7] apresentam um sistema especialista para a escolha de secadores.

Com base nos algoritmos propostos pelos diversos autores, a seleção e dimensionamento de secadores exigirão a coleta de informações sobre os equipamentos disponiveis. VAN'T LAND [11] e KEMP \& BAHU [4] assinalam que tais informações podem ser obtidas na literatura, junto ao fornecedor, pela experiência do engenheiro ou através de estudos em escala laboratorial.

Embora cada autor desenvolva seleção dos secadores de um modo próprio, identifica-se uma linha geral no procedimento de escolha do equipamento. Todos os autores estabelecem um roteiro ou um fluxograma com questionamentos segundo os quais somos dirigidos ao equipamento mais apropriado. [1]

\section{2 - REVISÃO BIBILIOGRÁFICA}

Para proceder à seleção do equipamento de secagem, primeiramente é feito um levantamento das informações do processo em que está inserida a etapa de secagem bem como do produto final desejado e da matéria-prima utilizada [8]. 
As informações fundamentais variam entre os autores embora um conjunto delas sejam comuns entre eles [2]:

\section{1 - Quantidades:}

- Produtividade em termos da massa seca (ex.: $\mathrm{kg} . / \mathrm{h})$;

- Fonte de matéria-prima. Se o processo anterior à secagem dá-se em batelada ou contínuo. Se em batelada, estabelecer as quantidades de cada batelada e a freqüência com que é reposta.

\section{2 - Propriedades físicas da matéria-prima:}

- Fonte de matéria-prima;

- Estágios de dessorção anteriores;

- Capacidade de armazenamento de matéria-prima;

- Método para alimentação do secador;

- Dimensão aproximada da partícula;

- Características físicas como a maneabilidade. Em caso de pastas indicar a possibilidade de serem préformadas;

- Abrasividade do material seco e da matéria-prima.

\section{3 - Propriedades químicas da matéria-prima:}

- Toxicidade do material líquido ou solido;

- Problemas de odor no material líquido ou solido;

- Sensibilidade do material aos gases de combustão;

- Possibilidade de explosão;

- Limites de temperatura e o tempo de exposição;

- Quais as possiveis mudanças de fases e a que temperatura/pressão ocorrem;

- Qual a corrosividade do material;

- Quais os materiais mais apropriados para a construção do secador que tolerem a corrosão.

\section{4 - Especificações do produto seco:}

- Umidade desejada no produto final;

- Métodos de detecção do solvente;

- Será necessário remover odor do solvente no produto final?

- Dimensões da partícula;

- Máximo percentual de impurezas aceito no produto final.

\section{5 - Propriedades do produto seco:}

- Desvantagens na formação de partículas menores;

- Propriedades de fluxo da matéria recentemente seca e da matéria fria;

- Temperatura a que o material deve ser resfriado para ser conservado evitando a aglomeração.

\section{6 - Dados de secagem disponiveis:}

- Detalhamento dos testes laboratoriais;

- Detalhamento dos testes em planta piloto;

- Detalhamento da performance de materiais semelhantes em escala real;

- Facilidade de pré-formação da matéria-prima ou mistura dos subprodutos de secagem para a formação de grãos.

\section{7 - Recuperação de solventes.}

\section{8 - Perdas:}

- Custo de produção na planta;

- A perda de pó para a atmosfera é só inoportuna ou consiste em risco?

9 - Local de operação:

- Disponibilidade de fontes de calor (gás, óleo e outros combustiveis);

- Detalhes do fornecimento de energia elétrica;

- Necessidades da purificação do ar de secagem e resfriamento;

- Necessidade de remoção do odor dos gases liberados para a atmosfera;

- Necessidades de reduzir a vibração e o barulho;

- Restrições de espaço;

- Facilidades para a supervisão do processo e manutenção;

- Disponibilidade de equipamentos para controle e manutenção.

Das informações obtidas, ainda que de forma qualitativa devemos ser capazes de responder às próximas questões [8]:

\section{1 - Limites de temperatura:}

- qual a máxima temperatura pode ser aceita no meio de aquecimento mantendo-se dentro das limitações do material?

\section{2 - Limitações do comportamento do material:}

- O material úmido é de difícil manuseio?

- Algum estado do material deve ser evitado para prevenir perda de material em pó?

- A taxa de secagem será limitada pela difusão interna?

\section{3 - Limitações construtivas:}

- Algum material especifico é necessário para as faces em contato com o material?

- O aquecimento indireto é necessário para impedir a contaminação do material pelos gases da queima?

- Há alguma outra circunstância especial esperada?

Com base neste conjunto de informações sobre o problema de secagem, devemos ser capazes de fazer a escolha do equipamento mais adequado [8].

Na revisão bibliográfica podemos notar dois mecanismos básicos para o desenvolvimento da seleção de secadores [1]:

\section{1 - Analitico:}

Em que uma seqüência de processos decisórios elimina os equipamentos inadequados à solução, conduzindo à determinação da melhor solução.

\section{2 - Numérico:}

Em que cada equipamento recebe uma pontuação de acordo com a sua adequação à solução do problema, na totalização, a melhor solução é a que obtém a maior pontuação. 
O modo mais antigo para se desenvolver o procedimento de escolha de um secador é o analitico, especialmente quando se toma em conta a importância do conhecimento acumulado para a escolha do equipamento. Como no mecanismo analítico os equipamentos inadequados à solução são eliminados, a melhor solução será única e determinada pela seqüência de decisões. LAPPLE, CLARK \&DYBDAL [6], NONHEBEL \& MOSS [8], VAN'T LAND [10], VAN'T LAND [11], PAPAGIANNES [9] utilizam-se deste procedimento para formular seus modelos de seleção.

Com o desenvolvimento dos computadores o método numérico tornou-se mais prático e rápido de ser aplicado. KEMP \& BAHU [4], KEMP [5], MATASOV, MENSHUTINA \& KUDRA [7] utilizam-se do procedimento numérico para formular seus modelos de seleção. Pode-se notar por BAKER \& LABADIBI [3] que o uso da lógica difusa abre espaço para um terceiro mecanismo, combinando o algoritmo analítico ao numérico.

No mecanismo numérico cada secador recebe um número de pontos de acordo com a sua adequação ao produto. Uma diferença importante entre este mecanismo e o qualitativo é que neste cada secador tem de ser testado para cada parâmetro do produto. Isto pode tornar mais lento o procedimento, embora certamente aumente a certeza sobre a opção correta. Com o desenvolvimento da informática a demora em testar cada equipamento vem perdendo importância frente à vantagem em fazer uma escolha mais acertada [1].

Outra forma de formalizar as relações entre os dados e a adequação dos equipamentos é estabelecer uma gradação, atribuindo uma pontuação para cada equipamento em relação ao produto. Os equipamentos mais adequados recebem um valor maior e os inadequados recebem nenhum valor ou um valor menor. Os valores das pontuações podem ser desequilibrados para favorecer um tipo de equipamento [1].

O mecanismo numérico é mais flexivel quanto aos resultados, como os equipamentos não são eliminados, ao final do processo em lugar de um resultado único, haverá uma ordem dos melhores equipamentos, deixando ao usuário a decisão final sobre o melhor equipamento.

NONHEBEL \& MOSS [8] desenvolvem de forma analitica a escolha do equipamento baseando-se na forma de alimentação:

\section{Seleção preliminar de secadores segundo a forma de alimentação:}

\section{1 - Liquidos (incluindo soluções coloidais e emulsões)}

Há uma grande dificuldade em manipular esta classe de produtos e a escolha dos equipamentos em geral estará restrita aos seguintes [8]:

- Secadores por atomização.

Obs.: O produto de um secadores por atomização terá propriedades físicas distintas dos produtos de outro secadores. Algumas vezes estas propriedades po- dem ser desejáveis.

- Secadores de Tambor (atmosférico ou a vácuo);

- Secador em batelada vibrátil a vácuo.

Outras considerações podem influenciar a escolha de um destes secadores:

$\rightarrow$ a necessidade de minimizar as perdas de produto;

$\rightarrow$ a necessidade de recuperação de solvente ou de uma atmosfera inerte, ocasião em que o secador em batelada vibrátil a vácuo pode ser preferido;

$\rightarrow$ a sensibilidade do material à temperatura: neste caso a escolha pode ficar entre o secador em batelada vibrátil a vácuo com um longo tempo de residência, um secador contínuo de esteira perfurada com circulação de ar cruzado com temperatura e tempo de residência moderados, um tambor com temperatura ligeiramente alta mas com um tempo de contato pequeno ou um secador por atomização com alta temperatura e um tempo de contato extremamente curto.

\section{2 - Suspensões finas e lamas}

As considerações para esta matéria-prima, bem como a lista de secadores possiveis, encaixam-se perfeitamente com as de líquidos. Entretanto, há uma chance menor de obter um produto uniforme em um secador por atomização.

\section{3 - Pastas e lodosos}

Nesta classe as dimensões do sólido apresentam uma grande variação e a preocupação com a formação de pó aumenta. A escolha entre secadores em batelada e contínuo não são específicas pois as dificuldades do processo contínuo em geral competem com as desvantagens do processamento em batelada.

$\rightarrow$ Em batelada:

- Em bandejas (atmosférico ou a vácuo);

- Em bandejas com agitação (atmosférico ou a vácuo);

- Rotativo (atmosférico ou a vácuo).

A operação a vácuo é restrita a situações em que seja necessária a recuperação de solvente, atender a limitações de temperatura e diminuir riscos.

$\rightarrow$ Contínuo:

- Atomizado quando a pasta tiver de ser atomizada; o que pode incorrer em uma trabalho experimental considerável;

- Leito fluidizado quando houver problemas na dispersão do material;

- Em esteira perfurada com circulação de ar cruzado este secador exigirá a pré-formagem na alimentação, principalmente se for necessário evitar a formação de pó;

- Pneumático (Flash) deve-se misturar parte do produto seco à matéria úmida para facilitar a dispersão na entrada do secador;

- Rotativo direto ou indireto deve-se misturar parte 
do produto seco à matéria úmida para facilitar a dispersão na entrada do secador. Em geral este tipo de produto contém partículas finas e deve-se preferir o rotativo indireto.

\section{4 - Filmes}

As considerações para esta matéria-prima, bem como a lista de secadores possiveis, encaixam-se perfeitamente com as de pastas e lodosos, exceto pela inclusão do secador vertical com bandejas rotativas, particularmente útil quando a redução de cristais é desejada.

\section{5 - Granulares, sólidos cristalinos e pré-formados pe- quenos}

Partículas de até $300 \mu \mathrm{m}$ devem ser consideradas como filmes. Para partículas acima de $300 \mu \mathrm{m}$, o uso de um secador rotativo direto é recomendado. Outro candidato é o secador continuo de esteira perfurada com circulação de ar cruzado ou com tela vibrátil, preferencialmente para partículas maiores que $1 \mathrm{~mm}$ e pré-formados pequenos.

\section{6 - Sólidos fibrosos}

Estes materiais retêm uma grande quantidade de água, mas secam relativamente fácil. Mesmo quando reduzidos ou floculados são de dificil ou impossivel fluidização. Estes materiais, em geral, são muito sensiveis à temperatura. Testes e secagem a diferentes temperaturas deverão determinar sua sensibilidade. Afora esta observação os sólidos fibrosos seguem as mesmas considerações de filmes, materiais granulares, sólidos cristalinos e pré-formados pequenos.

\section{7 - Outros materiais}

Outros materiais não contemplados, provavelmente se enquadram nas situações a seguir:

- Secadores de pequena escala - Sob estas condições a maioria dos materiais podem ser secos em secadores de bandeja sob condições atmosféricas ou a vácuo;

- Secador - liofilizador - É um processo dispendioso e deve ser considerado somente para produtos não suportam altas temperaturas e que tenham valor agregado;

- Secagem de sólidos de grandes dimensões e formas especiais - Materiais como cerâmicas são secos lentamente em estufas, altos fornos e câmaras aquecidas.

VAN'T LAND [11] também desenvolve de forma analítica a seleção de secadores. O procedimento se desdobra em um para equipamentos contínuos e outro para batelada (Figuras 1 e 2). Para capacidades produtivas superiores a $100 \mathrm{~kg} / \mathrm{h}$ freqüentemente é usado um secador contínuo, mas a escolha entre o processo continuo e batelada deve levar em conta os equipamentos que precedem e que se seguem à etapa de secagem.

KEMP \& BAHU [4] desenvolvem um algoritmo numérico em que os fatores que regem a seleção de secadores podem ser apresentados de duas formas:

\section{1 - Com base no equipamento}

Os secadores são classificados usando os critérios anteriores permitindo o desenvolvimento de uma árvore em que os desdobramentos conduzem aos diferentes tipos de secadores e seus sub-tipos.

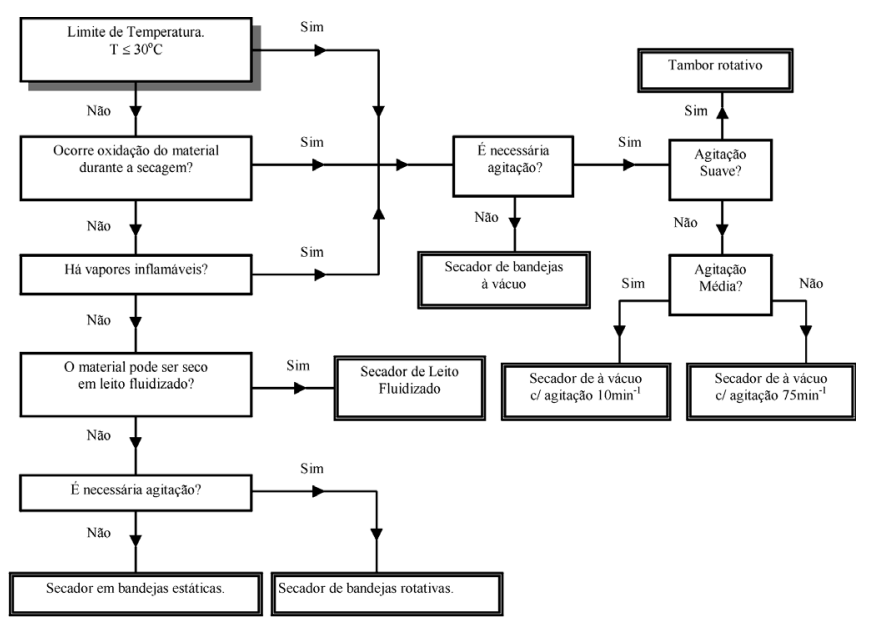

FIGURA 1 - Algoritmo de VAN'T LAND [10] para a seleção de secadores em batelada

\section{2 - Com base no produto}

É dado segundo a forma de manipulação das características da matéria-prima ; viscosidade, cinética de secagem e etc. Este pode incluir detalhes do processo como fluxo e umidade do material. Cada característica traz um impacto diferente sobre os equipamentos.

O seqüenciamento desenvolvido por KEMP \& BAHU [4] baseia-se no equipamento e segue a classificação proposta anteriormente. Ainda assim, é necessário analisar o efeito do material e os parâmetros de processo em cada opção estudada. Com este objetivo, um sistema de regras (com mais de 50 regras) foi desenvolvido compreendendo aspectos como dimensões da partícula, umidades inicial e final, fluxo de material etc. O algoritmo de busca é desenvolvido em cinco passos:

1- Passo - Definir o problema e obter os dados relevantes;

2- Passo - Escolha básica (formato, modo de aquecimento e operação);

3- Passo - Escolha dos tipos adequados (listar os secadores a serem dimensionados);

4- Passo - Sub-tipos e refinamentos (detalhamento e peculiaridades);

5 Passo - Análise das opções e escolha final.

A Figura 3 apresenta a estrutura de busca e a Figura 4 mostra o resultado típico de uma busca. A cada ponto a regra definirá se um equipamento é bom, inaceitável ou questionável. $\mathrm{O}$ ditos inaceitáveis podem ser eliminados ou, se forem considerados, deverão obter uma pontuação pifia frente aos equipamentos mais adequados [4]. 


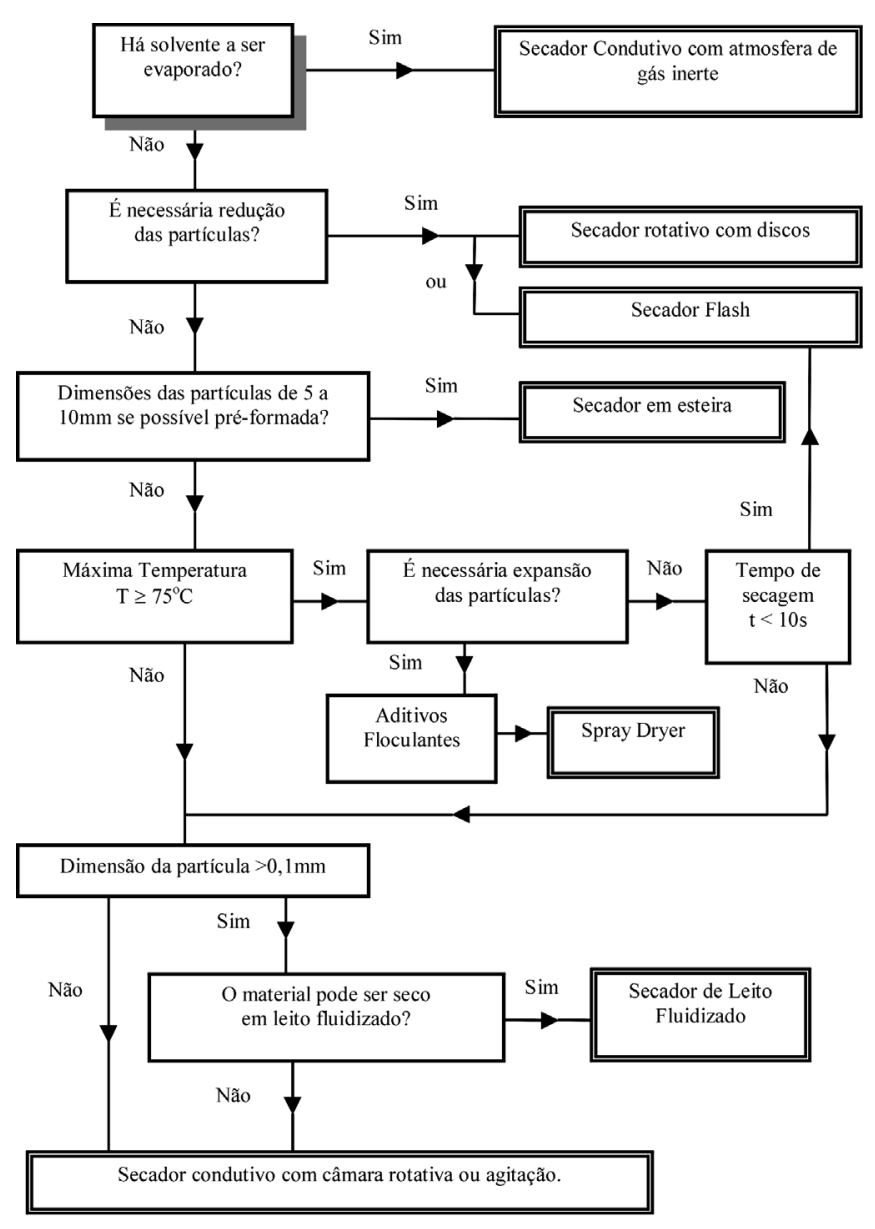

FIGURA 2 - Algoritmo de VAN'T LAND [10] para a seleção de secadores contínuos

Em muitos casos a regra pode tornar um secador indesejável, mas não proibitivo. Deste modo, a eliminação é inadequada pois poderá descartar prematuramente um equipamento não refletindo a complexidade do problema. Para que isto seja possivel, cada regra deverá gerar um fator de mérito (ou pontuação) para o equipamento. Ao final do algoritmo, as possiveis escolhas são ordenadas segundo o mérito. As maiores pontuações são escolhidas e as menores são rejeitadas.

KEMP \& BAHU [4] detalham cada passo dos estágios sem especificar as regras utilizadas no algoritmo.

\section{Passo - Definir o problema e obter os dados relevan- tes [4]}

Dados relevantes sobre o material e sobre o processo muitas vezes são muito variados de dificil acesso. Alguns podem ser encontrados no fluxograma de processo, outros na literatura e em tabela ou catálogos. Outros dados podem ser obtido experimentalmente em escala laboratorial. Invariavelmente haverá lacunas nas informações e a seleção deve ser capaz de lidar com este problema. As

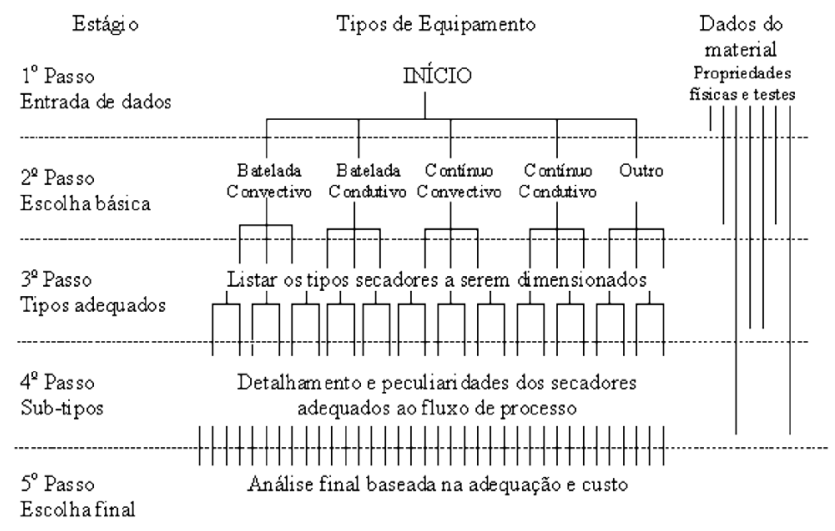

FIGURA 3 - Estrutura de busca [4]

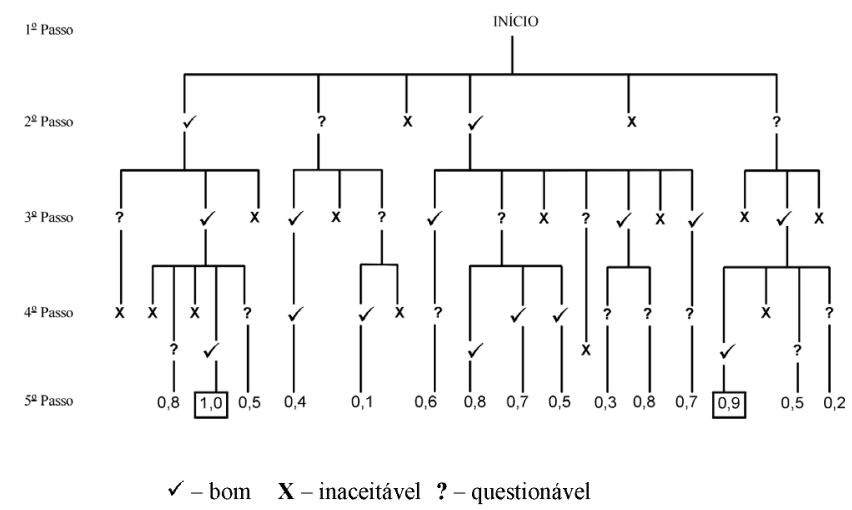

FIGURA 4 - Seqüência típica de busca [4]

informações podem ser obtidas quantitativa ou qualitativamente a adesividade, por exemplo, poderá ser dada como uma medida de força de coesão ou pela "impressão" de que o material é dificil de manipular.

Alguns itens acerca do produto deveriam ser conhecidos para a preparação do fluxograma de processo :

- Forma de alimentação do produto (pasta, pó, lâminas, etc.);

- Identificar o solvente a ser removido e o gás de secagem e suas propriedades fisicas;

- Taxa de produção desejada;

- Umidade de entrada e saída e final do produto; variação aceitável e níveis de impureza;

- Dimensões das partículas, forma e propriedades fisicas;

- Itens de processamento anteriores e posteriores ao secador.

Alguns testes em escala laboratorial podem ser realizados determinando propriedades fisicas, térmicas e mecânicas do material, entre elas:

- Cinética de secagem (taxas de secagem, velocidades 
do gás, temperatura, etc.);

- Umidade de equilíbrio;

- Exame ao microscópio (propriedades superficiais, aglomeração);

- Evaporador laboratorial (superaquecimento, adesão);

- Tambor rotativo (atrito e formação de pó);

- Bancada de aquecimento (decomposição térmica);

- Coesão/adesão (manuseio, efeito da umidade na adesão).

Obs.: Outros testes podem ser incluídos como o de fluidização.

\section{Passo - Escolha básica (formato, modo de aqueci- mento e operação) [4]}

Quatro decisões principais podem ser feitas limitando as opções de busca rapidamente:

- Forma de alimentação do produto, incluindo possibilidades de alteração no produto;

- Operação em batelada ou contínuo;

- Forma de aquecimento (contato, convectivo ou outro método);

- Se um secador de dois ou mais estágios é considerado como uma única peça.

a) Forma de alimentação do produto:

A maioria dos secadores pode lidar com particulados, mas só alguns podem lidar com pastas, lâminas e placas. Assim, para uma dada alimentação muitas opções podem ser eliminadas. Entretanto, a alteração do material antes da alimentação ou o pós processamento devem ser considerados e podem aumentar o número de alternativas. Uma pasta viscosa pode ser misturada com material seco, extrusada ou pré-formada.

As especificações do produto afetam fortemente a escolha do secador. Por exemplo, um produto em flocos é imediatamente obtido de um secador em tambor, enquanto um produto aglomerado, altamente poroso de baixa densidade é freqüentemente produzido em um secador por atomização. Outras especificações do produto como a retenção de aroma ou de outros componentes dominam a escolha do secador. Há situações em que o liofilizador é favorecido apesar do alto investimento e custo operacional.

\section{b) Operação em batelada ou contínuo.}

Secadores em batelada tendem a ser menores e são mais laboriosos pois cada batelada têm de ser carregada e descarregada. São favorecidos por taxas de produção pequenas, longos tempos de residência, outros equipamentos em batelada antes ou depois do secador ou necessidades de controle estrito. O secador contínuo é favorecido pelas condições, obviamente, contrárias a estas.

Cada uma destas condições pode ser analisada isoladamente ou em conjunto. Em geral, secadores em batelada dificilmente são adequados para produção acima de $1000 \mathrm{~kg} / \mathrm{h}$, enquanto os contínuos raramente são utilizados para produção abaixo de 50kg/h [8]. c) Forma de aquecimento

A escolha da forma de aquecimento é complexa. As mais utilizadas são as condutivas e convectivas.

Secadores convectivos que usam um fluxo maior de gás alcançam taxas de transferência de calor mais altas. Logo, estes secadores conseguem secar mais rapidamente, especialmente nos estágios iniciais de secagem, a perda de calor, porém, é alta. Se requer isolamento térmico ou contenção dos gases aquecidos o secador condutivo é favorecido. Quando há limitações de temperatura os secadores condutivos a vácuo são a melhor escolha. Contrariamente secadores convectivos são mais adequados a altas temperaturas.

A taxa de produção também tem um efeito importante. Secadores convectivos podem facilmente lidar com altos fluxos de sólidos em comparação aos condutivos, embora existam exceções como os secadores de leito deslizante e algumas unidades de fluxo cruzado.

As outras formas de aquecimento são mais especializadas. O custo em geral é muito mais alto que o das formas anteriores de aquecimento e o aproveitamento (conversão) energética é muito inferior [8].

d) Se um secador de dois ou mais estágios é considerado como uma única peça.

Dois secadores com características diferentes podem ser usados em série. Isto é mais freqüente, quando a cinética de secagem e a forma de manipulação do material mudam claramente ao longo do processo. Um exemplo deste primeiro caso é um secador pneumático que secaria um particulado até o ponto critico e em seguida seria transferido para um secador de bandejas com um tempo de residência longo. Um exemplo do segundo caso é um leito fluidizado com um estágio bem misturado e outro estágio pistonado, a transição é feita no momento em que o sólido fluidizado escapa do leito.

O algoritmo pode lidar com estas situações equacionando cada estágio em separado somando, em seguida, os resultados [8].

\section{$3^{\circ}$ Passo - Escolha dos tipos adequados (listar os seca- dores a serem dimensionados) [4]}

Neste passo um grande número de secadores provavelmente será considerado adequado. Usualmente, não é possivel afirmar que um secador nunca poderá ser utilizado, mas certamente será possivel dizer se um secador é mais ou menos adequado. A decisão final de prosseguir ou não com determinado equipamento deveria ser deixada para o usuário.

O objetivo desta etapa é definir um critério de pontuação para os secadores que não tenham sido eliminados no estágio anterior. Neste estágio as características do material e do processo são comparadas com a capacidade de cada secador se adaptar à estas condições. Um dimensionamento pode ser feito para descobrir condições de saída do material, tempo de residência, dimensões e 
custo.

Em todos os casos, com a dimensão aproximada, uma avaliação do custo poderá ser feita. Esta informação permitirá excluir secadores excessivamente grandes, caros ou inadequados.

\section{Passo - Sub-tipos e refinamentos (detalhamento e peculiaridades) [4]}

O princípio deste estágio é idêntico ao do estágio anterior, porém um número maior de detalhes são considerados. Cada equipamento selecionado no passo anterior possui sub-tipos. Por exemplo, há diversos tipos de agitadores para secadores em bandejas com agitação, alguns com aquecimento e outros não, o fluxo de massa e a faixa de adesividade com o qual o secador será capaz de lidar são variados. Nesta etapa, refinamentos como a recirculação de gás poderão ser considerados.

\section{Passo - Análise das opções e escolha final [4]}

As decisões decorrentes das considerações anteriores são apresentadas nesta etapa, alguns aspectos devem ser considerados: dos.

Destacar dois ou três dos secadores mais adequa-

- Indicar a vantagem e a desvantagem de cada escolha.

- Sugerir outras conformações e refinamentos que sejam benéficos ao secador.

Certamente o parâmetro final de escolha estará baseada no custo. Portanto, finalizando a seleção está o compromisso entre os custos de operação, qualidade do produto, segurança e facilidade de instalação. Destacam-se alguns pontos de comparação entre os secadores eleitos [10]:

- Custo instalado;

- A instalação esta correta ou pode esconder custos extras?

- Custos operacionais: energia, operação e manutenção;

- Perda de material: produto ou solvente;

- Segurança;

- O produto está na forma final? Se não qual o custo de outros processos?

- Se secadores com formas de alimentação diferentes estiverem sendo comparados, qual o custo para preparar formas alternativas de alimentação?

- O secador é flexível quanto à carga de material para produção?

- É importante o controle estrito do processo? Se sim quais as dificuldades de controle?

- Em caso de pequenos secadores e plantas de múltiplo uso, o secador é suficientemente versátil?

- Se for possível, fazer uma análise minuciosa do produto final de cada secador eleito para comparação;

- Outros pormenores.

É necessário que seja assinalado ao usuário que a avaliação dos custos é pouco precisa. Portanto, recomen- da-se que cada equipamento selecionado deva ser orçado com precisão. Só então seu custo poderá configurar como um parâmetro preciso de escolha.

\section{3 - NOVOS MODELOS DE SELEÇÃO}

Baseado nos modelos descritos, ALONSO [2] propõe dois modelos de seleção de secadores. O primeiro segue o processo analítico de decisão, o segundo estabelece regras e pontuações, seguindo o processo numérico.

Em ambos os modelos, o algoritmo de seleção foi dividido em, duas etapas seqüenciais fundamentais [2]:

1. Coleta de dados:

1.1. Do produto;

1.2. Do processo.

2. Seleção do secador adequado ao produto / processo:

2.1.Pré-seleção do tipo de secador;

2.2. Seleção do subtipo de secador (detalhamento).

Para uma escolha mais precisa outras três etapas podem ser adicionadas, perfazendo um total de cinco etapas para o algoritmo completo [2]:

3. Dimensionamento das peças selecionadas.

4. Avaliação econômica do equipamento dimensionado.

5. Escolha final do equipamento.

Em ambos os modelos, a primeira etapa é realizada pelo levantamento e tabulação das informações de produto e processo.

$\mathrm{Na}$ segunda etapa formalizam-se as relações entre os dados e a adequação dos equipamentos estabelecendo regras. No fluxograma de VAN'T LAND [10], Figura 2, por exemplo, há a decisão relacionada com a necessidade da remoção de solvente outro que não a água [2].

No modelo analítico, esta decisão pode ser expressa com base em uma variável booleana:

OUTRO_SOLVENTE $=($ 'FALSO' $=$ não ; 'VERDADEIRO' = $\operatorname{sim})$.

Desse modo a regra que rege o primeiro passo é:

SE há outro solvente, que não a água, a ser removido ENTÃO selecionar o secador condutivo com atmosfera de gás inerte SENÃO continue com a seleção [2].

No modelo numérico, a mesma decisão é feita atribuindo um ponto positivo aos secadores condutivos e nenhum ponto aos outros. Ou ainda, pode-se atribuir um ponto positivo a todos os secadores condutivos, e a todos os secadores com ambiente inerte.

Diferentemente do método qualitativo em que não é necessário testar cada equipamento, neste método, testa-se cada equipamento para cada variável e se atribuem pontuações segundo a adequação do equipamento ao produto.

Foram desenvolvidas regras em cada método para um grupo de 4 decisões:

- Primeira Decisão - Definir a necessidade de uso de vá- 
cuo ou atmosfera de gás inerte;

- Segunda Decisão - Quanto ao regime de processo;

- Terceira Decisão - Forma de aquecimento;

- Quarta Decisão - Quanto à forma de alimentação e manipulação do material.

Em ambos os modelos a terceira etapa (dimensionamento das peças selecionadas) é feita pelo cálculo da área de secagem de cada equipamento.

A quarta etapa (avaliação econômica) é feita pelo cálculo do custo operacional e do custo fixo do equipamento.

A escolha final do equipamento (quinta etapa) é alcançada, no método qualitativo, na segunda etapa, enquanto que no método numérico é alcançada pela comparação dos dados da avaliação econômica.

Quatro problemas de secagem foram formulados para testar a acuidade e eficiência dos modelos, como se segue [2]:

Secagem de cenoura: deseja-se secar uma produção de cenoura a uma taxa de $5 \mathrm{~kg} / \mathrm{h}$. A umidade inicial da cenoura é $10 \mathrm{~kg} / \mathrm{kg}$. A umidade final desejada é de 3 $\mathrm{kg} / \mathrm{kg}$;

Secagem de tâmara: deseja-se secar uma produção diária de $80 \mathrm{~kg}$ de tâmaras. A umidade inicial da tâmara é

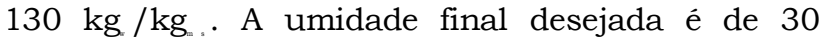
$\mathrm{kg} / \mathrm{kg}$;

Secagem de casca de ovo: deseja-se secar uma produção de cascas de ovo a uma taxa de $100 \mathrm{~kg} / \mathrm{h}$. A umida-

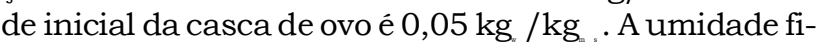
nal desejada é de $0,015 \mathrm{~kg} / \mathrm{kg}_{\text {, ; }}$

Secagem de menta: deseja-se secar uma produção de menta a uma taxa de $1 \mathrm{~kg} / \mathrm{h}$. A umidade inicial da men-

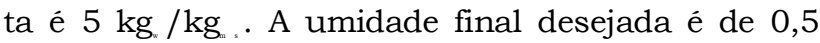
$\mathrm{kg} / \mathrm{kg}$. A temperatura de secagem não deve ultrapassar $40^{\circ} \mathrm{C}$.

No Quadro 1 apresentam-se os resultados obtidos dos modelos de seleção propostos.

Os algoritmos numérico e qualitativo produziram resultados coerentes. No primeiro e segundo problemas (cenoura e a tâmara), o secador fluidizado em batelada foi escolhido pelos dois algoritmos, com o secador em bandejas atmosférico como segunda alternativa. No terceiro problema (casca de ovo) os secadores rotativo direto e de bandejas contínuo não apenas obtiveram pontuação idêntica no procedimento numérico, como no procedimento qualitativo eles compõem uma resposta única. No quarto problema (tâmara e menta) o secador em bandejas a vácuo (condutivo) foi selecionado e mesmo secador com as bandejas agitadas foi a segunda alternativa [2].

A análise inicial dos resultados demonstra a coerência entre os métodos e confirma a expectativa antecipada de que o método numérico proveria alternativas de escolha do equipamento enquanto o qualitativo encerraria
QUADRO 1 - Quadro comparativo dos algoritmos de seleção [2]

\begin{tabular}{|l|c|c|c|}
\hline \multirow{2}{*}{ PROBLEMA } & \multicolumn{3}{|c|}{ ALGORITMO } \\
\cline { 2 - 4 } & QUALITATIVO & $\begin{array}{c}\text { PRIMEIRO } \\
\text { RESULTADO }\end{array}$ & $\begin{array}{c}\text { SEGUNDO } \\
\text { RESULTADO }\end{array}$ \\
\cline { 2 - 4 } A. Cenoura & $\begin{array}{c}\text { Secador de leito } \\
\text { fluidizado em } \\
\text { batelada }\end{array}$ & $\begin{array}{c}\text { Secador de leito } \\
\text { fluidizado em } \\
\text { batelada }\end{array}$ & $\begin{array}{c}\text { Secador de } \\
\text { bandejas } \\
\text { atmosférico }\end{array}$ \\
\hline B. Tâmara & $\begin{array}{c}\text { Secador de leito } \\
\text { fluidizado em } \\
\text { batelada }\end{array}$ & $\begin{array}{c}\text { Secador de leito } \\
\text { fluidizado em } \\
\text { batelada }\end{array}$ & $\begin{array}{c}\text { Secador de } \\
\text { bandejas } \\
\text { atmosférico }\end{array}$ \\
\hline C. Casca de ovo & $\begin{array}{c}\text { Secador convectivo } \\
\text { de bandejas contínuo } \\
\text { ou rotativo direto }\end{array}$ & \multicolumn{2}{|c|}{$\begin{array}{c}\text { Secador convectivo de bandejas } \\
\text { contínuo ou rotativo direto }\end{array}$} \\
\hline D. Menta & $\begin{array}{c}\text { Secador condutivo em } \\
\text { bandejas a vácuo }\end{array}$ & $\begin{array}{c}\text { Secador de } \\
\text { bandejas a vácuo }\end{array}$ & $\begin{array}{c}\text { Secador de } \\
\text { bandejas agitadas a } \\
\text { vácuo }\end{array}$ \\
\hline
\end{tabular}

um resultado único.

A escolha do equipamento em cada problema é coerente com a teoria na maioria dos problemas formulados. O secador fluidizado, resultante nos algoritmos numérico e qualitativo, tem sido utilizado na secagem de cenoura e o secador em bandejas resultante no algoritmo numérico, também é adequado para este processo. No problema formulado para menta o resultado também é coerente com a bibliografia. A limitação da temperatura de secagem em $50^{\circ} \mathrm{C}$ forçou a seleção dos sistemas a vácuo no algoritmo numérico e qualitativo.

O secador rotativo direto é perfeitamente adequado e é utilizado na secagem de casca de ovo. O secador em bandejas contínuo é menos utilizado mas também é adequado para este processo. É interessante observar, que os secadores em esteira com circulação de ar cruzado, de leito fluidizado contínuo e pneumático (flash), também utilizados na secagem de casca de ovo também são os melhores pontuados pelo algoritmo numérico. Na verdade o primeiro resultado seria composto pelo secador convectivo de bandejas contínuo e o rotativo direto enquanto o segundo resultado seriam estes outro secadores, perfeitamente coerente com a bibliografia [2].

Para a tâmara o resultado difere do esperado, as dimensões da tâmara não favorecem a utilização do secador fluidizado pois, o fluxo de ar necessário para a secagem é elevado e por conseguinte seu custo operacional desaconselha o uso deste equipamento, ainda assim ele foi o selecionado nos dois algoritmos. Porém, o segundo resultado obtido pelo algoritmo numérico é o secador em bandejas, mais adequado a este processo com uma área de secagem e custo fixo compativeis com a realidade [2].

Deste modo, para a cenoura, o melhor secador selecionado é o secador de leito fluidizado, o custo fixo e o custo operacional calculados para este equipamento são os mais baixos. Esta solução ratifica a solução obtida pelos algoritmos de seleção.

Para a menta o resultado do secador em bandejas a vácuo foi considerado único desconsiderando o uso de bandejas agitadas obtido na seleção do equipamento [2]. 
O resultado obtido para a tâmara permite inferir que os algoritmos de seleção priorizaram a menor área de secagem, que seria a do secador fluidizado, em detrimento do custo operacional, este certamente será alto dada às dimensões da tâmara. Esta deficiência do método poderá ser sanada com o refinamento do método criando novas regras para a seleção do equipamento e incluindo os aspectos formadores do custo operacional ao algoritmo. Uma regra possivel seria estabelecer uma faixa de diâmetro impedindo os materiais de grandes dimensões e que portanto exigem um fluxo de ar elevado para estes secadores.

Esta ocorrência demonstra ainda a vantagem do algoritmo numérico sobre o algoritmo qualitativo ao fornecer resultados alternativos, pois eventuais imprecisões do método seriam compensados na escolha do melhor secador.

\section{4 - CONCLUSÕES}

Três roteiros para a seleção de secadores foram apresentados, dois que operam pelo mecanismo analitico e um que opera pelo mecanismo numérico. Todos os métodos podem ser implementados computacionalmente. Os métodos analíticos são mais rápidos pois a cada decisão somente os secadores adequados são testados e os inadequados são eliminados. Isto pode levar a imprecisões eliminando secadores que em etapas posteriores no processo de escolha mostrar-se-iam adequados. Por outro lado, no método numérico, a cada decisão todos os secadores são testados. Isto eleva a precisão em detrimento da rapidez na escolha do equipamento. Com o desenvolvimento dos sistemas computacionais a alternativa numérica é mais interessante pois a rapidez com que a escolha é feita deixa de ser um fator decisivo.

Foram apresentados os resultados de dois modelos de seleção desenvolvidos: um qualitativo e outro numérico. Tais resultados demonstraram a validade dos modelos desenvolvidos. Nota-se ainda que o modelo numérico é ratificado por fornecer uma diversidade de resultados.

\section{5 - REFERÊNCIAS BIBLIOGRÁFICAS}

[1] ALONSO, L.F.T. ; PARK, K.J. ; BROD, F.P.R. Métodos de seleção de secadores In: Congresso Brasileiro de Engenharia Agricola, 29., 2000, Fortaleza-CE. Anais... Fortaleza: SBEA, 2000. CD-ROM.

[2] Alonso, L.F.T. Algoritmos de seleção e dimensionamento de secadores. Campinas, 2001. 204f. Tese (Doutorado, Pós-colheita) Curso de Pós Graduação em Engenharia Agrícola, Universidade Estadual de Campinas / UNICAMP.

[3] BAKER, C.G.J. ; LABADIBI, H.M.S. Application of fuzzy expert systems in dryer selection. In: 11 th International Drying Symposium (IDS'98), 1998, Halkidiki Greece. Proceedings... Thessaloniki-Grécia: Ziti Editions, August 19-22, 1998. v.A.. p.448-455.

[4] KEMP, I.C. ; BAHU, R.E. A new algorithm for dryer selection. Drying Technology. New York: Marcel Dekker Inc., n.13(5-7), p.1563-1578, 1995.

[5] KEMP, I.C. Progress in dryer selection techniques. In: 11th International Drying Symposium (IDS'98), 1998, Halkidiki Greece. Proceedings... Thessaloniki-Grécia: Ziti Editions, August 19-22, 1998. v.A. p.668-575.

[6] LAPPLE, W.C. ; CLARK, W.E. ; DYBDAL, E.C. Drying: design \& costs. Chemical Engineering. [S.1.:s.n.], November, p.177-200, 1955.

[7] MATASOV, A. ; MENSHUTINA, N. ; KUDRA, T. Information system for the selection of dryer In: 11th International Drying Symposium (IDS'98), 1998, Halkidiki Greece. Proceedings... Thessaloniki-Grécia: Ziti Editions, August 19-22, 1998. v.A.. p.624-619.

[8] NONHEBEL, G.M.A. ; MOSS, A.A.H. Drying of Solids in the Chemical Industry. Londres: Butterworth \& Co., 1971.301p.

[9] PAPAGIANNES, G.J. Select the right dryer. Chemical Engineering. [S.1.:s.n.], December, p20-27, 1992.

[10] VAN'T LAND, C.M. Industrial Drying Equipment: selection and application. New York: Marcel Dekker Inc, 1991. p.19-39.

[11] VAN'T LAND, C.M. Selection of industrial dryers. Chemical Engineering. [S.1.:s.n.], v. 5, n.91, p.53-61, 1984. 